\title{
American School Health Association Update
}

The American School Health Association invites you to join us for an unforgettable learning experience in Hawaii - a place of rich and diverse cultures and great beauty. From July 9 - 13, ASHA will be at the Ala Moana Hotel in Honolulu. The theme of this 81st Annual conference of ASHA is Health Literacy in Many Cultures. Health literacy, a public health priority, encompasses the cognitive and social skills that enable people to gain access to, understand, and use information to make informed choices. Developing literacy skills is a major function of schools, which are in a unique position to further the health literacy of students and staff. Many sessions will relate to improving health literacy individually, in the classroom or within groups and will contain an emphasis on coordinated school health.

As a keynote presentation, Marvlyn Kitashima will share her personal story of resiliency and her experiences as a participant in the Kauai Longitudinal Study on Resilience. Nancy Brener of CDC/DASH will release the first findings of the 2006 School Health Programs and Policies Study (SHPPS) during the All Conference Luncheon. Acting Surgeon General Vice Admiral Kenneth Moritsugu has focused much of his recent work on health literacy and has been invited as a third keynoter. In addition, ASHA will offer over 100 breakout sessions with programmatic, research, and teaching technique options plus a chance to meet with others at a series of Networking Lunches. The complete agenda and registration form are available at http://www.ashaweb.org/annual_conferences.html. The Hawaii Local Planning Team is working hard to arrange exciting and enriching activities, such as the night out luau.

ASHA offers a TEAM DISCOUNT to schools or school districts that bring four or more people to the conference. The \$30 per person discount includes full conference amenities plus a one-year ASHA membership. To take advantage of this offer, go to http://www.ashaweb.org/annual conferences.html, complete a registration form for each attendee and submit all at the same time with payment. Purchase Orders are accepted.

Susan F. Wooley, PhD, CHES

Executive Director

American School Health Association

7263 State Route 43 P. O. Box 708

Kent, Ohio 44240

Ph.: 330-678-1601

Fax.: 330-678-4526

E-Mail: swooley@ashaweb.org

http://www.ashaweb.org 